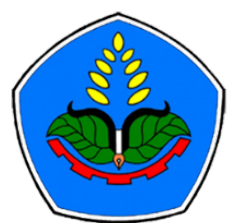

AGROPROSS

National Conference

Proceedings of Agriculture

\section{Proceedings:}

Peningkatan Produktivitas Pertanian Era Society 5.0 Pasca Pandemi

Tempat : Politeknik Negeri Jember

Tanggal : 22 Juli 2021

Publisher :

Agropross, National Conference Proceedings of Agriculture

ISBN : 978-623-94036-6-9

DOI : 10.25047 /agropross.2021.237

\title{
Model Peningkatan Pendapatan Agribisnis Tebu Rakyat
}

\author{
Author(s): Dede Kurniawan ${ }^{(1)^{*}}$, Amran Jaenudin $^{(1)}$, Wachdijono ${ }^{(1)}$ \\ (1) Fakultas Pertanian Universitas Swadaya Gunung Jati (UGJ) Cirebon \\ * Corresponding author: dede.kurniawan120588@gmail.com
}

\section{ABSTRACT}

Decent income is highly expected by all sugarcane agribusiness actors, because it is closely related to the existence of cultivation and their welfare, especially in this era of the covid-19 pandemic. However, in the last five years, the national income of sugarcane farmers has decreased, so efforts are needed to increase their income. This study aims to develop a model of government policy to increase sugarcane agribusiness income in Karangsuwung District, Cirebon Regency. Time of research in September-November 2020. The design of this research is quantitative with survey method. The research population was sugarcane farmers in the Sindang Laut Sugar Factory Working Area, Karangsuwung Sugar Factory, which amounted to 129 people and the sample size was determined to be 57 people. Data analysis uses path analysis and to test hypotheses using Sobel test. The results of the study concluded that there was a direct influence of the variable of improving the pattern of financing (credit) for sugarcane cultivation (X1) and the improvement of the pattern of cost of production/farmers' benchmark price (HPP) and the national sugar trade system (X4) on the increase in sugarcane agribusiness income $(Y)$ and there were the indirect effect of the variable of improving the pattern of financing (credit) for sugarcane cultivation (X1) and improving productivity $(X 2)$ on increasing sugarcane agribusiness income (Y) through improving the pattern of cost of production/farmers' benchmark price (HPP) and the national sugar trade system (X4). Through this research, it is hoped that it can become a local and national reference on the model of increasing people's sugarcane agribusiness income.
\end{abstract}

Keywords:

cirebon; government policy; increased revenue; sugarcane farmers: cane.

\section{Kata Kunci: ABSTRAK}

cirebon;

kebijakan pemerintah;

peningkatan pendapatan;

petani tebu;

tebu
Pendapatan yang layak sangat diharapkan oleh semua pelaku agribisnis tebu, dikarenakan sangat berkaitan dengan eksistensi budidaya dan kesejahteraannya, apa lagi pada era pandemic covid-19 ini. Namun dalam lima tahun terakhir, pendapatan petani tebu secara nasional menurun, sehingga diperlukan upaya agar pendapatannya meningkat. Penelitian ini bertujuan menyusun model kebijakan pemerintah untuk meningkatkan pendapatan agribisnis tebu di Kecamatan Karangsuwung Kabupaten Cirebon. Waktu penelitian pada bulan September-November 2020. Desain penelitian ini adalah kuantitatif dengan metode survey. Populasi penelitian adalah petani tebu di Wilayah Kerja Pabrik Gula Sindang Laut Rayon Pabrik Gula Karangsuwung yang berjumlah 129 orang dan besar sampel ditentukan sebesar 57 orang. Analisis data menggunakan analisis jalur (path analysis) dan untuk menguji hipotesis menggunakan sobel test. Hasil penelitian menyimpulkan terdapat pengaruh langsung dari variabel perbaikan pola pembiayaan (kredit) budidaya tebu (X1) dan perbaikan pola harga pokok produksi/harga patokan petani (HPP) dan tata niaga gula nasional (X4) terhadap peningkatan pendapatan agribisnis tebu (Y) dan terdapat pengaruh tidak langsung dari variabel perbaikan pola pembiayaan (kredit) budidaya tebu (X1) dan perbaikan produktivitas (X2) terhadap peningkatan pendapatan agribisnis tebu (Y) melalui perbaikan pola harga pokok produksi/harga patokan petani (HPP) dan tata niaga gula nasional (X4). Melalui penelitian ini diharapkan dapat menjadi referensi lokal dan nasional tentang model peningkatan pendapatan agribisnis tebu rakyat. 


\section{PENDAHULUAN}

Agribisnis merupakan kegiatan usaha berbasis pertanian yang memiliki subsistem dari hulu ke hilir yang saling berkaitan satu dengan yang lainnya, salah satu subsistem yang mampu memberikan kontribusi yang besar terhadap perekonomian di Indonesia adalah subsistem sektor agroindustri. Badan Pusat Statistik (BPS) merilis pertumbuhan ekonomi Indonesia pada kuartal I tahun 2019 sebesar 5,07 \% secara year on year (YOY), pertumbuhan Product Domestic Brutto (PDB) di sektor pertanian pada kuartal ini positif atau mengalami peningkatan dengan kontribusi sebesar 1,81 \% (Ismail, 2019).

Sehubungan dengan hal di atas, Ketua Dewan Komisioner Otoritas Jasa Keuangan (OJK), menyebutkan sektor pertanian merupakan sektor kedua yang memiliki kontribusi terbesar terhadap PDB Indonesia. Oleh karenanya sektor pertanian menjadi sangat penting sebab lebih dari $50 \%$ DB dari sektor industri pengolahan adalah berbasis pertanian. Selain itu, sektor pertanian juga menyerap tenaga kerja terbesar, yakni sekitar $35 \%$ dari total tenaga kerja. Jika sektor pertanian dipandang secara holistik dari hulu hingga hilir dalam suatu rantai nilai, maka kontribusinya sekitar $55 \%$. Meningkatnya kontribusi sektor pertanian terhadap pertumbuhan ekonomi nasional tentu tidak terlepas dari upaya pemerintah. Beberapa upaya dilakukan untuk mendorong peningkatan produksi pangan, terutama untuk komoditas strategis melalui peningkatan Luas Tambah Tanam (LTT), serta memberikan berbagai bantuan sarana dan prasarana pertanian (Lestari, 2017).

Kondisi sektor pertanian di Indonesia saat ini dihadapkan pada permasalahan pengusahaan ekonomi skala kecil dengan jumlah penguasaan lahan yang kecil dan penerapan teknologi budidaya yang masih sederhana, serta akses permodalan yang terbatas. Pertanian dengan skala kecil tersebut masih dipengaruhi oleh faktor alam dan harus menghadapi permasalahan pasar yang tidak sempurna, seperti tingginya biaya transaksi dan tidak ada kejelasan informasi dari pasar sebagai tempat bagi para petani untuk menjual hasil produksi pertanian mereka. Selain itu, para petani dengan skala kecil masih harus menghadapi permasalahan lain seperti ketersediaan sarana produksi pertanian (saprotan) seperti pupuk, bibit, pestisida, dan obatobatan. Untuk mengatasi permasalahan di sektor pertanian khususnya petani dengan skala kecil yaitu mengintegrasikan petani ke dalam sektor industri agar para petani dianggap lebih modern. Hal tersebut adalah basis yang melatar belakangi lahirnya konsep kemitraan (contract farming/partnership) dan Peraturan Pemerintah No. 44 Tahun 1997 adalah Landasan yang mengatur konsep kemitraan di Indonesia yang menyebutkan bahwa kemitraan merupakan kerjasama antara usaha kecil dengan memperlihatkan prinsip saling memerlukan, saling memperkuat dan saling menguntungkan (Alam \& Hermawan, 2017).

Industri gula merupakan salah satu agroindustri yang memegang peranan penting dalam perekonomian indonesia. hal ini disebabkan karena posisinya sebagai salah satu komoditas strategis yang menjadi tulang punggung ketahanan ekonomi dengan berbasis sumber daya nasional yang memiliki struktur keterkaitan dan kedalaman yang kuat serta memiliki daya saing yang tangguh di pasar internasional. Pabrik gula Indonesia saat ini berjumlah 60 pabrik gula yang masih aktif dimana 43 pabrik dikelola oleh BUMN dan 17 pabrik dikelola oleh swasta dengan luas area tebu yang dikelola saat ini mencapai 473.000 hektar dengan total produksi sebesar 3.159.836 ton. Persebaran area tebu sekitar 289.000 hektar atau $61 \%$ berada di Jawa dan selebihnya berada di Lampung dan Sulawesi Selatan. Dari luasan pertanaman tebu di Jawa tersebut, 
sekitar $40 \%$ diusahakan di lahan sawah dan $60 \%$ di lahan tegalan (Muaddab, 2014).

Direktorat Jendral Industri dan Agro Kimia, (2009) mengatakan Kebutuhan terhadap gula sebagai salah satu sumber kalori di dunia terus meningkat. Peningkatan ini dapat ditunjukkan dari pertumbuhan konsumsi gula dunia dengan laju 0,7 \% pada tahun 2005-2006. Konsumsi gula yang meningkat juga terjadi di Indonesia dengan pertumbuhan konsumsi mencapai 4,2 - 4,7 \% pada tahun 2009 (Kimia 2009). Saat ini, permintaan komoditas gula jumlahnya terus mengalami peningkatan sejalan dengan pertambahan jumlah penduduk, peningkatan pendapatan masyarakat, serta semakin berkembangnya usaha industri makanan dan minuman yang menggunakan bahan bakunya gula. Dengan permintaan gula yang terus meningkat setiap tahun telah menyebabkan pemenuhan produksi gula di dalam negeri tidak bisa mencukupi, jumlah realisasi angka produksi gula nasional pada tahun 2015 angkanya mencapai 2497.000 ton yang dihasilkan dari areal perkebunan tebu yang ada sebesar 446.060 hektar. Sedangkan, angka kebutuhan konsumsi gula nasional setiap tahunnya membutuhkan kurang lebih sebesar 5.000.000 ton sehingga produksi gula mengalami defisit jumlahnya mencapai 2.503.000 ton setiap tahun. Pada tahun 2016 diperkirakan stok gula nasional hanya mencapai 3.317 .000 juta ton dan untuk menutupi kebutuhan konsumsi di dalam negeri yang tidak mencukupi tersebut diusahakan melalui impor gula.

Pada tahun 2018 sebanyak 2.170 .000 ton sementara kebutuhan gula nasional mencapai 6.600.000 ton. Produksi gula nasional saat ini dipasok oleh 48 pabrik gula milik Badan Usaha Milik Negara (BUMN) dan 17 pabrik gula milik swasta. Dengan adanya, kesenjangan antara kebutuhan akan konsumsi gula dengan produksi gula yang dihasilkan tersebut maka diperlukannya adanya impor gula dari luar negeri. Namun pemerintah telah mengupayakan untuk menekan volume impor pada tahun 2019 hanya memberikan izin kuota impor gula industri sekitar 2.800.000 ton kuota impor ini turun sekitar $1,29 \%$ dibandingkan tahun lalu sebanyak 3.600 .000 ton. Pemotongan impor gula dilakukan karena digudang-gudang industri gula masih ada sekitar 1.000.000 ton (Ismail, 2019).

Ketimpangan antara harga gula dipasaran dan harga gula ditingkat petani dipertanyakan banyak pihak baik dari lingkungan pabrik gula maupun masyarakat petani tebu. Kebijakan (regulasi) menjadikan kesenjangan yang seakan-akan tidak ada keterkaitan antara petani dengan pabrik gula baik dalam permasalahan rendemen ataupun perlindungan lahan dari pemerintah. Teknik budidaya yang selama ini dilakukan seakan tidak memberikan harapan perbaikan terhadap kenaikan pendapatan para petani tebu karena beberapa regulasi yang diterapkan oleh pemerintah tidak berdampak besar pada peningkatan pendapatan petani tebu. Pendapatan petani tebu selama periode 2015-2019 menurun pendapatn sehingga minat masyarakat untuk menanam tebu mengalami penurunan yang sangat drastis. Berdasarkan uraian di atas, maka dapat diidentifikasi permasalahannya yaitu bagaimana model peningkatan pendapatan usaha tani tebu rakyat melalui kebijakan Pemerintah di Wilayah Pabrik Gula Sindang Laut Rayon Karangsuwung?

\section{METODOLOGI PENELITIAN Desain dan Teknik Penelitian}

Desain yang digunakan dalam penelitian adalah metode kuantitatif deskriptif, menurut (Sugiyono 2007), metode kuantitatif dapat diartikan sebagai metode penelitian yang berlandaskan pada filsafat positivism, digunakan untuk meneliti pada populasi atau sampel tertentu, pengumpulan data menggunakan 
instrument penelitian, analisis data bersifat kuantitatif/statistik.

\section{Teknik Pengambilan Sampel}

Populasi Pengambilan sampel yang digunakan dalam penelitian ini yaitu menggunakan teknik Simple random sampling. Teknik ini dikatakan sederhana (Simple) karena pengambilan anggota sampel dari populasi dilakukan secara acak tanpa memperhatikan tingkat pendidikan yang ada didalam populasi itu. Cara demikian dilakukan bila populasi dianggap homogen (Sugiyono, 2007). Berdasarkan hasil survei diperoleh data kelompok tani tebu diwilayah Pabrik Gula Sindang Laut Rayon Karangsuwung yang masih aktif bercocok tanam tebu sebanyak 8 kelompok tani tebu dengan jumlah popuasi petani sebanyak 129 orang sedangkan metode penentuan besar (jumlah) sampel dilakukan dengan menggunakan Rumus Slovin sebagai berikut:

$n=\frac{N}{1+N(\alpha)^{2}}$

Dimana:

$\mathrm{n}$ : Jumlah Sampel

$\mathrm{N}$ : Jumlah Populasi

$\alpha$ : Persen kelonggaran ketidak telitian karena pengambilan sample yang dapat ditolelir (10\%)

\section{Analisis Deskriptif}

Analisis deskriptif dalam penelitian ini menggunakan metode Likert's Summated Rating (LSR) berdasarkan pada sejumlah skor dari seluruh pernyataan yang diamati. Likert's Summated Rating (LSR) adalah metode pengukuran sikap (attitude) yang banyak digunakan dalam penelitian sosial karena kesederhanaannya. LSR sangat bermanfaat untuk membandingkan skor tiap perorangan dengan distribusi skala dari sekelompok orang lainnya, serta untuk melihat perkembangan atau perubahan sikap sebelum dan sesudah eksperimen atau kegiatan (Sugiyono, 2007). Adapun nilai skor penggunaan
Likert's Summated Rating (LSR) terdiri dari 5 - 1 dengan penjelasan sebagai berikut:

1) Sangat Setuju (SS) diberi bobot nilai 5

2) Setuju (S) diberi bobot nilai 4

3) Cukup Setuju (CS) diberi bobot nilai 3

4) Kurang Setuju (KS) diberi bobot nilai 2

5) Tidak Setuju (TS) diberi bobot nilai 1 Dapat ditentukan skor kriterium dengan menggunakan interval kelas dengan menggunakan rumus sebagai berikut:

$\mathrm{i}=\frac{\mathrm{R}}{\mathrm{I}}$

Dimana :

$\mathrm{i}=$ Interval Kelas

$\mathrm{R}=$ Range (data tertinggi-data terendah)

$\mathrm{I}=$ Jumlah Kelas

\section{Analisis Jalur (Path Analysis)}

Dalam penelitian ini, menggunakan model persamaan dua jalur. Model ini diaplikasikan untuk menentukan model peningkatan pendapatan petani tebu melalui kebijakan pemerintah yang terdiri dari 2 variabel independen (exogenous) terhadap variabel dependen (endogenous). Dengan dua variabel eksogen dan satu variabel endogen maka rumus yang dignakan adalah:

$$
\begin{gathered}
Y=\rho y x_{1} X_{1}+\rho y x_{2} X_{2}+\rho y x_{3} X_{3} \\
+\rho y x_{4} X_{4}+\varepsilon
\end{gathered}
$$

\section{Dimana:}

$Y \quad=$ Variabel Endogen

$X_{1}, X_{2}, X_{3}, X_{4} \quad=$ Variabel Eksdogen

${ } y x_{1} \quad=$ Adalah Koefisien Jalur

Variabel $\mathrm{X}_{1}$ Terhadap Y

pyx $_{2}=$ Adalah Koefisien Jalur

Variabel $\mathrm{X}_{2}$ Terhadap Y

$\rho y x_{3}=$ Adalah Koefisien Jalur

Variabel $\mathrm{X}_{3}$ Terhadap Y

$\rho x_{4}=$ Adalah Koefisien Jalur

Variabel $\mathrm{X}_{4}$ Terhadap Y

( $) \quad=$ Adalah Epsilon Menyatakan besarnya sisa pengaruh (residu), yang besarnya pengaruh dari variabel-variabel yang tidak diteliti.

Teknik analisis jalur, yang dikembangkan oleh Sewal Wright di tahun 1934 sebenarnya merupakan pengembangan korelasi. Lebih lanjut, 
analisis Jalur merupakan perluasan dari regresi liniear berganda dan yang memungkinkan analisis model-model yang lebih kompleks (Steiner, 2005). Menurut (Retherford, 1993), analisis jalur merupakan teknik untuk menganalisis hubungan sebab akibat yang terjadi pada regresi berganda jika variabel bebasnya mempengaruhi variabel intervening dan variabel terikat tidak hanya secara langsung tetapi juga secara tidak langsung.

\section{Uji Sobel Tes}

Ghozali (2018), mengatakan uji sobel digunakan untuk menghitung nilai variabel mediasi yang berdistribusi secara normal. Pada penelitian ini variabel mediasi atau variabel intervening adalah minat investasi. Untuk menghitung nilai dari signifikasi variabel pengaruh intervening alat yang digunakan adalah uji sobel.

\section{Teknik Pengumpulan Data}

Teknik pengumpulan data pada penelitian dilakukan dengan cara wawancara dengan para petani tebu serta pembagian kuesioner kepada para petani dengan dokumentasi. Menurut (Sanusi, 2011), wawancara merupakan teknik pengumpulan data yang menggunakan pertanyaan secara lisan kepada subjek penelitian. Menurut (Sugiyono, 2007), kuesioner merupakan teknik pengumpulan data yang dilakukan dengan cara memberikan seperangkat pertanyaan atau pernyataan tertulis kepada responden.

\section{HASIL DAN PEMBAHASAN \\ Analisis Deskriptif Perbaikan Pola Pembiayaan (Kredit) Budidaya Tebu $\left(\mathrm{X}_{1}\right)$}

Berdasarkan hasil perhitungan pada variabel perbaikan pola pembiayaan (kredit) budidaya tebu $\left(\mathrm{X}_{1}\right)$ menunjukkan bahwa perbaikan pola pembiayaan (kredit) budidaya tebu memiliki total skor sebesar $2.120(71,86 \%)$, dengan demikian variabel perbaikan pola pembiayaan (kredit) budidaya tebu termasuk ke dalam kategori menghendaki, yang artinya diperlukan perbaikan dalam pola pembiayaan (kredit) budidaya tebu agar dapat meningkatkan semangat masyarakat sekitar pabrik gula untuk kembali bercocok tanam tebu.

\section{Deskriptif Perbaikan/ Revitalisasi Pabrik Gula $\left(\mathbf{X}_{3}\right)$}

Berdasarkan hasil perhitungan variabel perbaikan/revitalisasi pabrik gula menunjukkan bahwa perbaikan/revitalisasi pabrik gula memiliki total skor 1.343 $(75,88 \%)$, dengan demikian variabel perbaikan/revitalisasi pabrik gula termasuk ke dalam kategori menghendaki, yang artinya diperlukan perbaikan pabrik gula untuk lebih mengefisiensikan proses industrialisasi gula kristal putih. Dengan perbaikan/revitalisasi pabrik gula yang merupakan komponen yang menunjang petani tebu untuk mendapatkan kualitas gula yang maksimal dan berdaya saing global dengan menerapkan SNI dan ISO.

\section{Analisis Deskriptif Perbaikan Pola Penetapan Harga Pokok Produksi/ Harga Patokan Petani (HPP) dan Sistem Tata Niaga Gula Nasional $\left(\mathrm{X}_{4}\right)$}

Berdasarkan hasil perhitungan variabel perbaikan pola penetapan harga pokok produksi/harga patokan petani (HPP) dan sistem tata niaga gula nasional menunjukkan bahwa total skor dari variabel perbaikan pola penetapan harga pokok produksi/harga patokan petani (HPP) dan sistem tata niaga gula nasional sebesar 2.162 (73,29\%), dengan demikian variabel perbaikan pola penetapan harga pokok produksi/harga patokan petani (HPP) dan sistem tata niaga gula nasional termasuk ke dalam kategori menghendaki, yang artinya diperlukan perbaikan pola penetapan harga pokok produksi/harga patokan petani (HPP) dan sistem tata niaga gula nasional. Dengan penetapan (HPP) oleh pemerintah yang lebih baik lagi maka 
akan menjadi tolak ukur pendapatan petani tebu dalam proses budidaya tebu dari offfarm sampai dengan on-farm.

\section{Analisis Deskriptif Peningkatan Pendapatan Usaha Tani Tebu (Y)}

Pendapatan adalah seluruh penerimaan baik berupa uang maupun berupa barang yang berasal dari pihak lain maupun hasil industri yang dinilai atas dasar sejumlah uang dari harta yang berlaku saat itu. Pendapatan merupakan sumber penghasilan seseorang untuk memenuhi kebutuhan sehari - hari dan sangat penting artinya bagi kelangsungan hidup dan penghidupan seseorang secara langsung mau pun tidak langsung (Suroto, 1992).

\section{Analysis Path/ Analisis Jalur}

Analisis jalur digunakan untuk mengukur seberapa besar pengaruh dari masing-masing variabel exdogen (Independen) terhadap variabel endogen (Dependen). Dalam penelitian ini terdapat empat (4) variabel X yaitu, Perbaikan Pola Pembiayaan $\left(\mathrm{X}_{1}\right)$, Perbaikan Produktivitas $\left(\mathrm{X}_{2}\right)$, Perbaikan Pabrik Gula $\left(\mathrm{X}_{3}\right)$, Perbaikan Pola HPP dan Tata Niaga Gula Nasional $\left(\mathrm{X}_{4}\right)$. Untuk mengetahui pengaruh dari masing-masing variabel dimaksud dapat dilihat pada tabel berikut:

Tabel 1. Pengaruh Dari Masing-Masing Variabel

Coefficients $^{\mathrm{a}}$

\begin{tabular}{|c|c|c|c|c|c|c|}
\hline & \multirow[t]{2}{*}{ Model } & \multicolumn{2}{|c|}{$\begin{array}{c}\text { Unstandardized } \\
\text { Coefficients } \\
\end{array}$} & \multirow{2}{*}{$\begin{array}{c}\begin{array}{c}\text { Standardized } \\
\text { Coefficients }\end{array} \\
\text { Beta }\end{array}$} & \multirow[t]{2}{*}{$\mathbf{t}$} & \multirow[t]{2}{*}{ Sig. } \\
\hline & & $\mathbf{B}$ & Std. Error & & & \\
\hline \multirow[t]{5}{*}{1} & (Constant) & 1.162 & 5.675 & & .205 & .839 \\
\hline & Perbaikan Pola Pembiayaan $\left(\mathrm{X}_{1}\right)$ & .324 & .111 & .312 & 2.915 & .005 \\
\hline & Perbaikan Produktivitas $\left(\mathrm{X}_{2}\right)$ & .183 & .140 & .162 & 1.307 & .197 \\
\hline & Perbaikan Pabrik Gula $\left(\mathrm{X}_{3}\right)$ & .210 & .154 & .142 & 1.361 & .179 \\
\hline & $\begin{array}{l}\text { Perbaikan Pola HPP dan Tata Niaga Gula } \\
\text { Nasional }\left(\mathrm{X}_{4}\right)\end{array}$ & .349 & .119 & .353 & 2.928 & .005 \\
\hline
\end{tabular}

Dependent Variable: Peningkatan Pendapatan Usaha Tani Tebu

Sumber : Olah Data IBM SPSS Statistic Versi 25

Berdasarkan tersebut dapat dijelaskan sebagai berikut:

1. Diketahui nilai sig. untuk pengaruh $\mathrm{X} 1$ terhadap $\mathrm{Y}$ adalah sebesar $0,005<0,05$, sehingga dapat disimpulkan bahwa H0 ditolak artinya terdapat pengaruh yang signifikan antara X1 terhadap Y.

2. Diketahui nilai sig. untuk pengaruh $X 2$ terhadap $Y$ adalah sebesar $0,197>0,05$, sehingga dapat disimpulkan bahwa H0 diterima artinya tidak terdapat pengaruh yang signifikan antara X2 terhadap Y.

3. Diketahui nilai sig. untuk pengaruh X3 terhadap Y adalah sebesar 0,179>0,05, sehingga dapat disimpulkan bahwa H0 diterima yang artinya tidak terdapat pengaruh yang signifikan antara X3 terhadap Y.

4. Diketahui nilai sig. untuk pengaruh $\mathrm{X} 4$ terhadap $\mathrm{Y}$ adalah sebesar $0,005<0,05$, sehingga dapat disimpulkan bahwa H0 ditolak yang artinya terdapat pengaruh yang signifikan antara X1 terhadap Y.

5. Berdasarkan analysis path diperoleh nilai koefisien variabel X1, X2, X3 dan X4 terhadap Y, nilai pengaruh langsung dan nilai pengaruh tidak langsung sebagaimana dapat dilihat pada Tabel berikut:

Tabel 2. Nilai Pengaruh Langsung Dan Nilai Pengaruh Tidak Langsung

\begin{tabular}{cccccccrrr}
\hline \multirow{2}{*}{ Var } & Koefisien & \multicolumn{2}{c}{ Pengaruh } & \multicolumn{3}{c}{ Pengaruh Tidak Langsung } & \multicolumn{2}{c}{ Total Pengaruh } & Total \\
& Beta & Langsung & $\mathrm{X}_{1}$ & $\mathrm{X}_{2}$ & $\mathrm{X}_{3}$ & $\mathrm{X}_{4}$ & Tidak Langsung & Pengaruh \\
\hline $\mathrm{X}_{1}$ & 0,312 & 0,097 & & 0,015 & 0,007 & 0,026 & 0,048 & 0,145 \\
$\mathrm{X}_{2}$ & 0,162 & 0,026 & 0,015 & & 0,005 & 0,031 & 0,041 & 0,076 \\
$\mathrm{X}_{3}$ & 0,142 & 0,020 & 0,007 & 0,005 & & 0,005 & 0,017 & 0,037 \\
$\mathrm{X}_{4}$ & 0,353 & 0,125 & 0,026 & 0,031 & 0,005 & & 0,062 & 0,187 \\
\hline Jumlah Total Pengaruh & & & & & & $\mathbf{0 , 4 4 6}$ \\
\hline
\end{tabular}


Tabel tersebut menunjukkan bahwa terdapat pengaruh langsung antara variabel $\mathrm{X}$ ke variabel $\mathrm{Y}$ dan terdapat pengaruh pengaruh tidak langsung antara variabel $\mathrm{X}$ ke variabel $Y$ melalui variabel $X$ lainnya.
Artinya antara variabel $\mathrm{X}$ dapat menjadi variabel intervening. Mengenai danya pengaruh langsung dan tidak langsung dapat dilihat pada Gambar berikut:

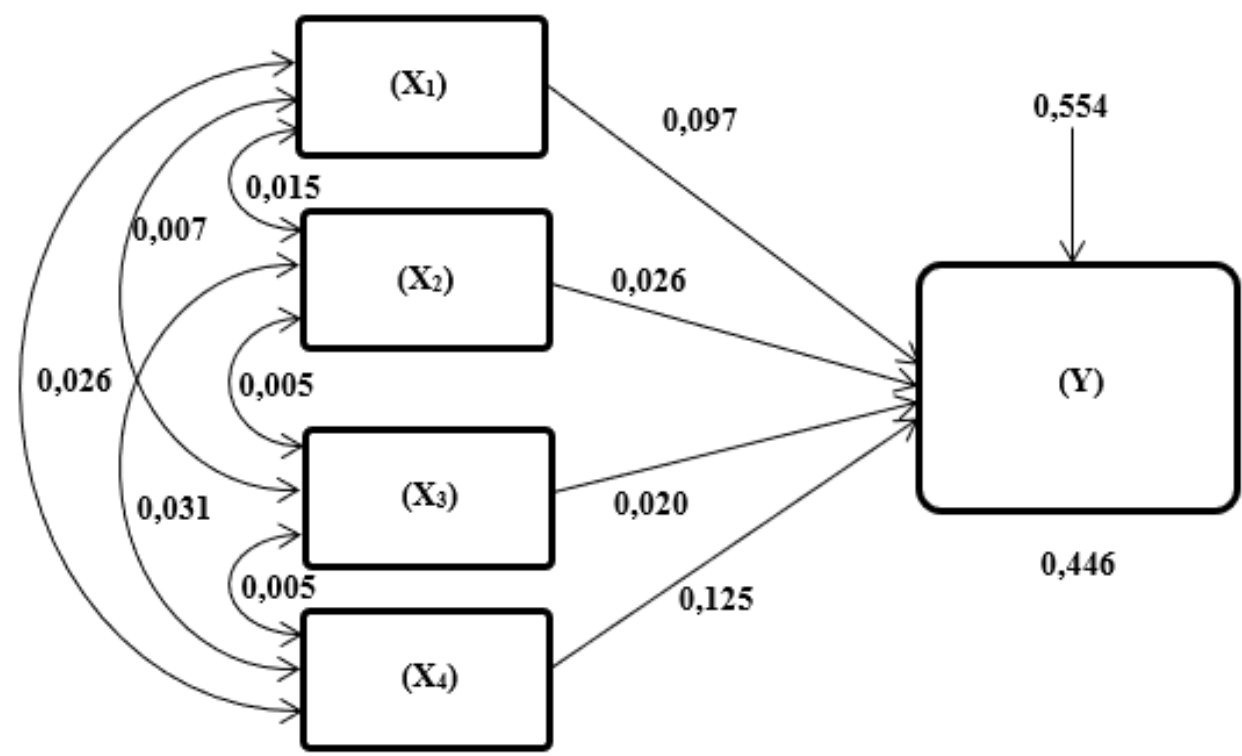

Gambar 1. Variabel Intervening Mengenai Daya Pengaruh Langsung dan Tidak Langsung

Uji Sobel Tes

Pada penelitian ini variabel mediasi atau variabel intervening adalah minat investasi. Variabel mediasi atau variabel intervening akan mempengaruhi antar variabel bebas dan variabel terikat. Berikut hasil Sobel Test mengenai pengaruh variabel $\mathrm{X}$ terhadap variabel $\mathrm{Y}$ melalui variabel $\mathrm{X}$, sebagai berikut:

\section{Sobel test pengaruh tidak langsung $X_{1}$ ke $Y$ melalui $X_{2}$, diketahui bahwa nilai:}

- Pengaruh langsung dari $X_{1}$ ke $Y$ sebesar 0,097

- Pengaruh tidak langsung $X_{1}$ ke $Y$ melalui $\mathrm{X}_{2}=\mathrm{P}_{2} \times \mathrm{P}_{3}(0,015 \times 0,031)$ $=0,0005$

- Sobel Test $\mathrm{X}_{1}$ ke Y melalui $\mathrm{X}_{2}$

$$
\begin{gathered}
\mathrm{SP}_{2} \mathrm{P}_{3}= \\
\sqrt{\mathrm{P}_{3}^{2} \mathrm{SP}_{2}^{2}+\mathrm{P}_{2}^{2} \mathrm{SP}_{3}^{2}+\mathrm{SP}_{2}^{2} \mathrm{SP}_{3}^{2}} \\
=\sqrt{(0,031)^{2}(0,111)^{2}+(0,015)^{2}(0,140)^{2}+(0,111)^{2}(0,140)^{2}}
\end{gathered}
$$

$$
=0,0161
$$

Berdasarkan perhitungan di atas, maka t hitung pada sobel test adalah:

$t_{\text {hitung }}=\frac{\mathrm{P}_{2} \mathrm{P}_{3}}{\mathrm{SP}_{2} \mathrm{P}_{3}}$

$t_{\text {hitung }}=\frac{0,0004}{0,0161}$

$t_{\text {hitung }}=0,0290$ (Tidak Signifikan 0,05)

$t_{\text {hitung }}<\mathrm{t}_{\text {tabel}}$, maka dapat disimpulkan bahwa koefisien mediasi 0,0004 tidak signifikan, artinya tidak dapat pengaruh mediasi $\mathrm{X}_{1}$ ke $\mathrm{Y}$ melalui $\mathrm{X}_{2}$.

2. Sobel test pengaruh tidak langsung $X_{1}$ ke $Y$ melalui $X_{3}$, diketahui bahwa nilai:

- Pengaruh langsung dari $\mathrm{X}_{1}$ ke $\mathrm{Y}$ sebesar 0,097

- Pengaruh tidak langsung $X_{1}$ ke $Y$ melalui $\mathrm{X}_{3}=\mathrm{P}_{2} \times \mathrm{P}_{3}(0,007 \times 0,020)$ $=0,0001$

- Sobel Test $\mathrm{X}_{1}$ ke Y melalui $\mathrm{X}_{3}$ 


$$
\begin{aligned}
& \mathrm{SP}_{2} \mathrm{P}_{3}= \\
& \sqrt{\mathrm{P}_{3}^{2} \mathrm{SP}_{2}^{2}+\mathrm{P}_{2}^{2} \mathrm{SP}_{3}^{2}+\mathrm{SP}_{2}^{2} \mathrm{SP}_{3}^{2}} \\
& =\sqrt{(0,020)^{2}(0,111)^{2}+(0,007)^{2}(0,154)^{2}+(0,111)^{2}(0,154)^{2}} \\
& =0,0174
\end{aligned}
$$

Berdasarkan perhitungan di atas, maka t hitung pada sobel test adalah:

$t_{\text {hitung }}=\frac{\mathrm{P}_{2} \mathrm{P}_{3}}{\mathrm{SP}_{2} \mathrm{P}_{3}}$

$t_{\text {hitung }}=\frac{0,0001}{0,0174}$

$\mathrm{t}_{\text {hitung }}=0,0081$ (Tidak Signifikan 0,05)

thitung $<$ tabel, maka dapat disimpulkan

bahwa koefisien mediasi 0,0001 tidak signifikan, artinya tidak terdapat pengaruh mediasi $\mathrm{X}_{1}$ ke $\mathrm{Y}$ melalui $\mathrm{X}_{3}$.

\section{Sobel test pengaruh tidak langsung} $\mathrm{X}_{1}$ ke $\mathrm{Y}$ melalui $\mathrm{X}_{4}$, diketahui bahwa nilai:

- Pengaruh langsung dari $\mathrm{X}_{1}$ ke $\mathrm{Y}$ sebesar 0,097

- Pengaruh tidak langsung $\mathrm{X}_{1}$ ke $\mathrm{Y}$ melalui $\mathrm{X}_{4}=\mathrm{P}_{2} \times \mathrm{P}_{3}(0,026 \times 0,125)$ $=0,0033$

- Sobel Test $\mathrm{X}_{1}$ ke Y melalui $\mathrm{X}_{4}$ $\mathrm{SP}_{2} \mathrm{P}_{3}=$ $\sqrt{\mathrm{P}_{3}^{2} \mathrm{SP}_{2}^{2}+\mathrm{P}_{2}^{2} \mathrm{SP}_{3}^{2}+\mathrm{SP}_{2}^{2} \mathrm{SP}_{3}^{2}}$

$$
\begin{aligned}
& \quad= \\
& \sqrt{(0,125)^{2}(0,111)^{2}+(0,026)^{2}(0,119)^{2}+(0,111)^{2}(0,119)^{2}} \\
& =0,0201
\end{aligned}
$$

Berdasarkan perhitungan di atas, maka $\mathrm{t}$ hitung pada sobel test adalah:

$t_{\text {hitung }}=\frac{\mathrm{P}_{2} \mathrm{P}_{3}}{\mathrm{SP}_{2} \mathrm{P}_{3}}$

$t_{\text {hitung }}=\frac{0,0033}{0,0201}$

$t_{\text {hitung }}=0,1617$ (Signifikan 0,05)

$t_{\text {hitung }}>t_{\text {tabel, }}$ maka dapat disimpulkan

bahwa koefisien mediasi 0,0033 signifikan, artinya terdapat pengaruh mediasi $\mathrm{X}_{1}$ ke $\mathrm{Y}$ melalui $\mathrm{X}_{3}$
4. Sobel test pengaruh tidak langsung $\mathrm{X}_{2}$ ke $\mathrm{Y}$ melalui $\mathrm{X}_{3}$, diketahui bahwa nilai:

- Pengaruh langsung dari $\mathrm{X}_{2}$ ke $\mathrm{Y}$ sebesar 0,026

- Pengaruh tidak langsung $\mathrm{X}_{2}$ ke $\mathrm{Y}$ melalui $\mathrm{X}_{3}=\mathrm{P}_{2} \times \mathrm{P}_{3}(0,026 \times 0,125)$ $=0,0001$

- Sobel Test $X_{2}$ ke Y melalui $X_{3}$ $\mathrm{SP}_{2} \mathrm{P}_{3}=$ $\sqrt{\mathrm{P}_{3}^{2} \mathrm{SP}_{2}^{2}+\mathrm{P}_{2}^{2} \mathrm{SP}_{3}^{2}+\mathrm{SP}_{2}^{2} \mathrm{SP}_{3}^{2}}$ $=\sqrt{(0,020)^{2}(0,140)^{2}+(0,005)^{2}(0,154)^{2}+(0,140)^{2}(0,154)^{2}}$ $=0,0218$

Berdasarkan perhitungan di atas, maka thitung pada sobel test adalah:

$t_{\text {hitung }}=\frac{\mathrm{P}_{2} \mathrm{P}_{3}}{\mathrm{SP}_{2} \mathrm{P}_{3}}$

$t_{\text {hitung }}=\frac{0,0001}{0,0218}$

$t_{\text {hitung }}=0,0046$ (Tidak Signifikan 0,05)

thitung $<$ tabel, maka dapat disimpulkan bahwa koefisien mediasi 0,0001 tidak signifikan, artinya tidak terdapat pengaruh mediasi $\mathrm{X}_{1}$ ke $\mathrm{Y}$ melalui $\mathrm{X}_{3}$.

\section{Sobel test pengaruh tidak langsung} $X_{2}$ ke $Y$ melalui $X_{4}$, diketahui bahwa nilai:

- Pengaruh langsung dari $\mathrm{X}_{2}$ ke $\mathrm{Y}$ sebesar 0,026

- Pengaruh tidak langsung $X_{2}$ ke $Y$ melalui $\mathrm{X}_{4}=\mathrm{P}_{2} \times \mathrm{P}_{3}(0,031 \times 0,125)$ $=0,0039$

- Total pengaruh langsung langsung dan pengaruh tidak langsung sebesar 0,145

Sobel Test $\mathrm{X}_{2}$ ke Y melalui $\mathrm{X}_{4}$

$$
\begin{aligned}
& \quad \mathrm{SP}_{2} \mathrm{P}_{3}= \\
& \sqrt{\mathrm{P}_{3}^{2} \mathrm{SP}_{2}^{2}+\mathrm{P}_{2}^{2} \mathrm{SP}_{3}^{2}+\mathrm{SP}_{2}^{2} \mathrm{SP}_{3}^{2}} \\
& =\sqrt{(0,125)^{2}(0,140)^{2}+(0,031)^{2}(0,119)^{2}+(0,140)^{2}(0,119)^{2}} \\
& =0,0244
\end{aligned}
$$


Berdasarkan perhitungan di atas, maka t hitung pada sobel test adalah:

$t_{\text {hitung }}=\frac{\mathrm{P}_{2} \mathrm{P}_{3}}{\mathrm{SP}_{2} \mathrm{P}_{3}}$

$t_{\text {hitung }}=\frac{0,0039}{0,0244}$

$t_{\text {hitung }}=0,1585$ (Signifikan 0,05)

$t_{\text {hitung }}>t_{\text {tabel}}$, maka dapat disimpulkan

bahwa koefisien mediasi 0,0039 signifikan, artinya terdapat pengaruh mediasi $\mathrm{X}_{2}$ ke $\mathrm{Y}$ melalui $\mathrm{X}_{4}$.

\section{Sobel test pengaruh tidak langsung $X_{3}$ ke Y melalui $X_{4}$, diketahui bahwa nilai:}

- Pengaruh langsung dari $X_{3}$ ke $Y$ sebesar 0,020

- Pengaruh tidak langsung $X_{3}$ ke $Y$ melalui $\mathrm{X}_{4}=\mathrm{P}_{2} \times \mathrm{P}_{3}(0,031 \times 0,125)$ $=0,0006$

- $\quad$ Sobel Test $\mathrm{X}_{3}$ ke Y melalui $\mathrm{X}_{4}$ $\mathrm{SP}_{2} \mathrm{P}_{3}=$

$$
\begin{aligned}
& =\sqrt{(0,125)^{2}(0,154)^{2}+(0,005)^{2}(0,119)^{2}+(0,154)^{2}(0,119)^{2}} \\
& =0,0266
\end{aligned}
$$

Berdasarkan perhitungan di atas, maka thitung pada sobel test adalah:

$t_{\text {hitung }}=\frac{\mathrm{P}_{2} \mathrm{P}_{3}}{\mathrm{SP}_{2} \mathrm{P}_{3}}$

$t_{\text {hitung }}=\frac{0,0006}{0,0266}$

$t_{\text {hitung }}=0,0235$ (Tidak Signifikan 0,05)

thitung $<$ tabel, maka dapat disimpulkan

bahwa koefisien mediasi 0,0006 tidak signifikan, artinya tidak terdapat pengaruh mediasi $\mathrm{X}_{3}$ ke $\mathrm{Y}$ melalui $\mathrm{X}_{4}$.

Berdasarkan hasil Sobel Test di atas, maka dapat disimpulkan bahwa variabel Y dipengaruh langsung oleh variabel X4 dan dipengaruhi secara tidak langsung oleh variabel X1 dan X2. Oleh karenanya, X4 berkedudukan sebagai variabel mediasi atau intervening. Dengan demikian, dapat disusun modelnya sebagaimana dapat dilihat pada Gambar berikut:

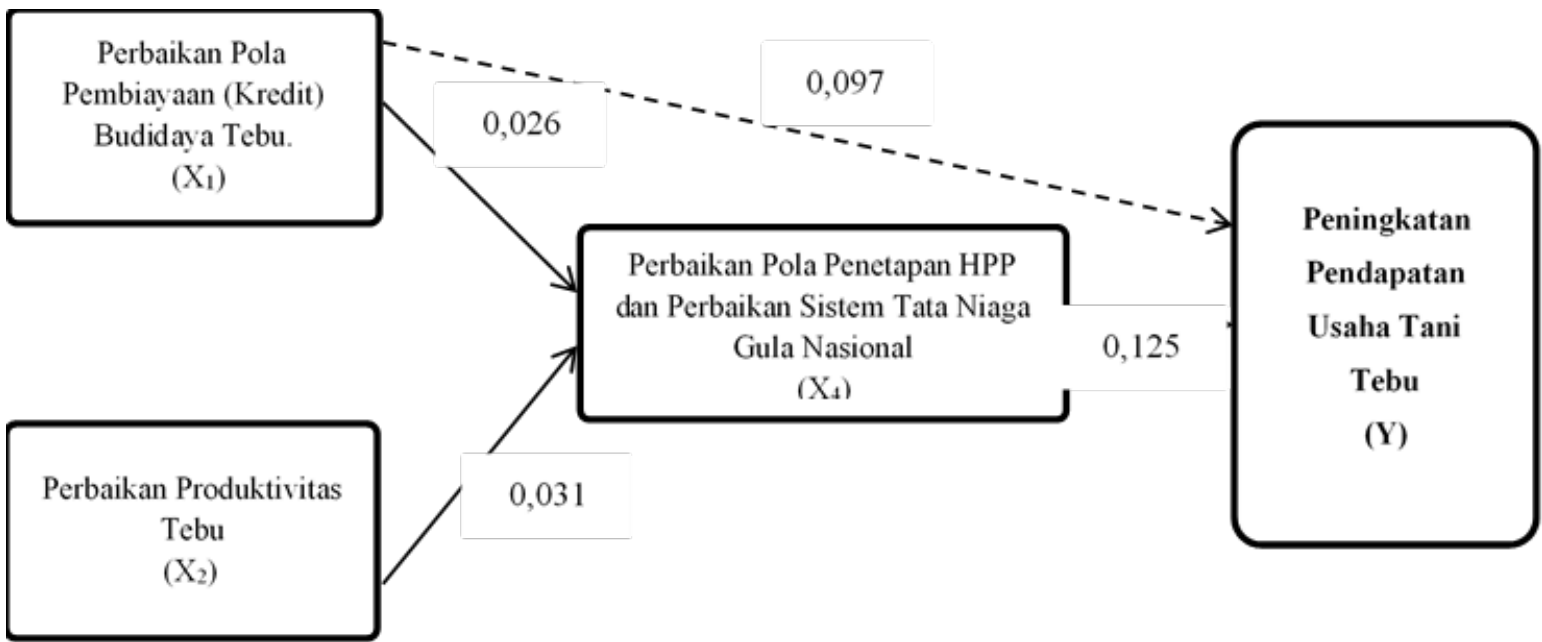

Gambar 2. Variabel Intervening (Mediasi) Dalam Upaya Meningkatkan Pendapatan Usaha Tani Tebu

Berdasarkan Gambar tersebut dapat dijelaskan bahwa X4 dapat menjadi variabel intervening (mediasi) dalam upaya meningkatkan pendapatan usaha tani tebu (Y), artinya perbaikan pola pembiayaan (kredit) budidaya tebu (X1) dan perbaikan produktivitas tebu (X2) dapat meningkatkan pendapatan usaha tani tebu (Y) melalui perbaikan pola penetapan harga pokok produksi/ harga patokan petani (HPP) dan tata niaga gula nasional (X4). Gambar tersebut relevan dengan penelitian yang dilakukan oleh (Sudaryono 2011) yang menyimpulkan bahwa alam 
suatu penelitian kuantitatif, suatu metode yang mengkaji urutan sebab akibat antara sejumlah variabel dalam suatu model penelitian disebut metode path analysis (analisis jalur). Dikarenakan pemikiran sebab akibat memainkan peranan atau aturan yang sangat penting dimana path analysis (analisis jalur) tersebut diaplikasikan, maka dengan menampilkan unsur-unsur path analysis (analisis jalur) dengan menerapkan analisis korelasi di antara sesama variabel berdasarkan urutan pengaruhnya, akan memberikan gambaran betapa pentingnya analisis jalur ini untuk diketahui oleh peneliti. Tujuan analisis jalur adalah menerangkan pengaruh langsung dan pengaruh tidak langsung seperangkat antar variabel, sebagai variabel penyebab, terhadap variabel lainnya yang merupakan variabel akibat.

\section{Pembahasan}

Penelitian ini menemukan bahwa untuk meningkatkan pendapatan usahatani tebu di wilayah kerja pabrik gula Sindang Laut Rayon Pabrik Gula Karangsuwung lebih didominasi oleh variabel perbaikan pola penetapan harga pokok produksi/ harga patokan petani (HPP) dan tata niaga gula nasional (X4) dari pada variabel perbaikan pola pembiayaan (kredit) budidaya (X1) dan variabel perbaikan produktivitas tebu (X2), Oleh karena itu, indikator-indikator pada variabel perbaikan pola penetapan harga pokok produksi/ harga patokan petani (HPP) dan tata niaga gula nasional (X4) harus lebih diperhatikan, diantaranya adalah penetapan harga pokok produksi/harga patokan petani (HPP) tata niaga gula nasional.

Dengan memperbaiki pola harga pokok produksi/harga patokan petani (HPP) dan tata niaga gula nasional yang lebih berpihak kepada petani dengan memperhatikan biaya-biaya produksi yang dikeluarkan oleh petani tebu dan menstabilkan harga lelang gula petani tebu dengan menekan import gula baik gula kristal rafinasi (raw sugar) maupun gula kristal putih saat panen raya, banyaknya bantuan dari pemerintah sebagai stimulant para petani tebu dalam menjalankan usaha tani tebu dirasa sia-sia saat panen raya tebu para petani tidak mendapatkan harga yang sesuai dengan jerih payah petani tebu selama satu tahun menjalankan usaha tani tebu. Harga Patokan Petani (HPP) yang diinginkan oleh para petani tebu berdasarkan aspirasi yang disampaikan melalui Lembaga Asosiasi Petani Tebu Rakyat Indonesia (APTRI) kepada Presiden Joko Widodo pada tanggal 6 Februari 2019 di Istana Negara adalah sebesar Rp. 10.500,-.

Selain itu perbaikan pola pembiayaan (kredit) budidaya tebu $\left(\mathrm{X}_{1}\right)$ dengan mempermudah persyaratan pengajuan pembiayaan kepada perbankan akan menambah minat masyarakat untuk kembali bercocok tanam tebu, dan perbaikan produktivitas tebu $\left(\mathrm{X}_{2}\right)$ dengan mengembangkan teknologi-teknologi pertanian yang ada harus ditunjang dengan sarana produksi pertanian yang memadai dan canggih sebagai upaya perbaikan produktivitas tebu agar mendapatkan nilai rendemen yang maksimal.

Hasil penelitian ini sejalan dengan penelitian yang dilakukan oleh Chandio et al., (2021) yang menyimpulkan bahwa kredit (pembiayaan) berpengaruh terhadap produktivitas tebu. skema kredit pertanian, harus mampu menyediakan kredit (pembiayaan) yang tepat waktu selama musim tanam tanaman tebu menjadi prasyarat penting untuk memastikan pemanfaatan kredit (pembiayaan) yang tepat yang tepat sesuai peruntukannya.

Saputri dan Respatiadi (2018), dalam penelitiannya mengatakan Pemerintah Indonesia memiliki peraturan menteri yang bertujuan untuk meningkatkan produktivitas gula dalam negeri yaitu Peraturan Menteri Pertanian (Permentan) Nomor 53 Tahun 2015 berfokus pada 
perbaikan praktik on-farm dengan cara memperbaiki teknik budidaya tebu melalui pengembangan varietas unggul, perkiraan waktu tanam yang tepat, dan sosialisasi praktik penanaman yang baik. Peraturan ini juga berfungsi untuk menjamin kesejahteraan petani tebu dan pekerja pabrik gula dengan memberikan mereka asuransi kesehatan, makanan dan minuman, dan, bila perlu, perawatan medis.

Penelitian lainnya yang dilakukan oleh Sulaiman et al. (2019), yang menyimpulkan bahwa untuk meningkatkan produktivitas tebu dan gula kristal putih di Indonesia harus ditempuh dengan memilih area baru untuk pengembangan lahan perkebunan tebu, konsolidasi tanah dan varietas unggul untuk meningkatkan produksi tebu dan restrukturisasi/revitalisasi pabrik gula dan pembangunan pabrik baru kunci untuk meningkatkan produksi gula. Maksimalisasi produktivitas, serta meningkatkan luas lahan perkebunan tebu, keduanya dibutuhkan untuk memenuhi kebutuhan gula. Strategi dan program yang direkomendasikan untuk memenuhi permintaan gula di Indonesia dibagi menjadi tiga aspek:

1. Meningkatkan produksi tebu yang meliputi peningkatan produktivitas tebu, pengurangan susut pada waktu panen, dan meningkatkan efisiensi pertanian. Selain itu, ekstensifikasi melalui lahan baru pembangunan dan pemantapan lahan diperlukan untuk meningkatkan produksi tebu.

2. Meningkatkan rendemen gula dan produk tambahan melalui: Revitalisasi pabrik gula yang sudah ada, pendirian pabrik baru di luar Jawa, dan pengembangan industri hilir.

3. Membangun lingkungan yang memungkinkan untuk memastikan dua program pertama dapat berjalan secara efisien dan efektif. Ini termasuk pembangunan infrastruktur, pengembangan investasi, manusia peningkatan kapasitas, penguatan kelembagaan, dan sinergisme kebijakan.

Penelitian lain yang sejalan dengan penelitian ini adalah penelitian yang dilaksanakan oleh Pusat Kebijakan Perdagangan Dalam Negeri Badan Pengkajian Dan Pengembangan Kebijakan Perdagangan Kementerian Perdagangan (2015), dalam Laporan Akhir Analisis Lelang Gula PTPN/Petani Dalam Rangka Stabilitas Harga yang dipublikasikan pada bulan Desember 2015 yang menyimpulkan bahwa penjualan gula PG dan petani umumnya dilakukan secara lelang sesuai dengan Keputusan Menteri Perindustrian dan Perdagangan Nomor 643/MPP/Kep/9/2002 yang disempurnakan dengan Keputusan Menteri Perindustrian dan Perdagangan Nomor 527/MPP/Kep/9/2002, selain itu dapat memberikan beberapa manfaat bagi produsen gula, antara lain untuk mendorong penciptaan harga yang transparan, kompetitif, inklusif serta proses penjualan yang efisien, meminimalkan tindakan koruptif dan kolusi, petani akan mendapatkan harga tertinggi, dan mendorong penjualan agar berjalan efisien.

Penelitian yang sejalan juga dilakukan oleh Adhiem (2018), mengatakan kebijakan impor gula yang dilakukan pemerintah dalam rangka upaya untuk menjaga pasokan gula nasional yang diperuntukkan bagi industri makanan dan minuman, hal menimbulkan kekhawatiran gula produksi lokal tidak akan terserap pasar yang berdampak besar terhadap penurunan harga jual gula lokal dan merugikan banyak petani tebu. Untuk itu kebijakan impor gula perlu ditinjau ulang oleh pemerintah dan memastikan jumlah kuota impor gula untuk menghindari penumpukan gula lokal akibat kejenuhan pasar serta diperlukan pengawasan untuk memastikan tidak ada kebocoran gula impor ke pasar lokal agar tidak 
menimbulkan kerugian terhadap petani tebu.

Tayibnapis, Wuryaningsih, dan Sundari (2016) mengatakan Perkembangan industri berbasis tebu di Indonesia sangat sulit diwujudkan hingga 5 (lima) tahun mendatang karena ketidakmampuan pemerintah mengatasi berbagai permasalahan mendasar, seperti biaya operasional yang tinggi, kandungan rendemen tanaman tebu yang rendah, performa mesin yang kurang maksimal, impor gula yang tidak sesuai dengan kebutuhan dalam negeri yang menyebabkan pasar berlebih dan tidak adanya sinergisitas antar kementerian/lembaga negara yang terkait dengan kebijakan industri gula nasional yang pada akhirnya menimbulkan benturan kepentingan sehingga swasembada gula tidak dapat tercapai.

\section{Implikasi Manajerial Dari Hasil Penelitian}

Berdasarkan hasil pembahasan tersebut, maka selanjutnya dapat dibuat sebuah implikasi manajerial yaitu Model Peningkatan Pendapatan Agribisnis Tebu Rakyat yang dapat dilihat pada gambar berikut:

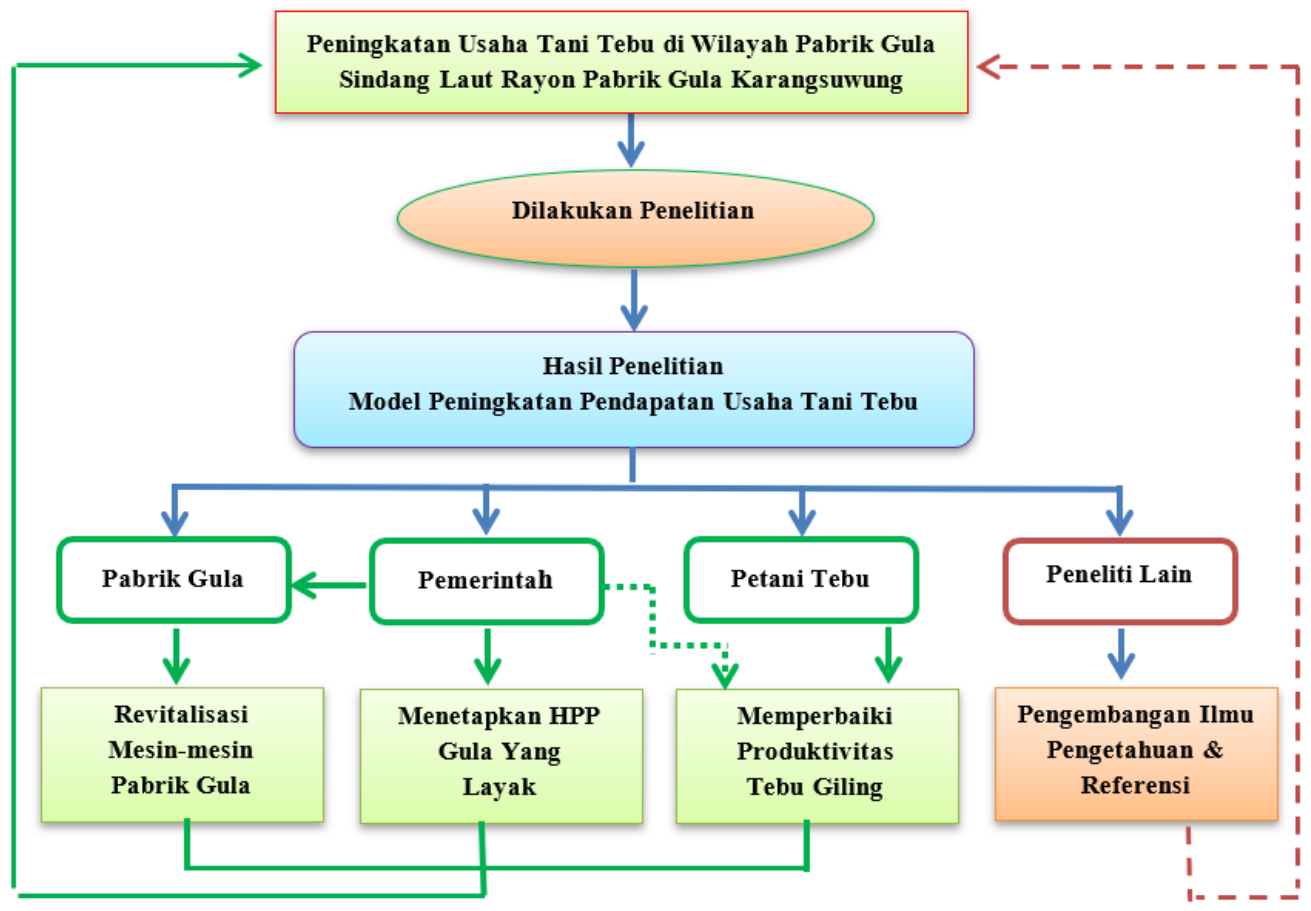

Gambar 2 Model Peningkatan Pendapatan Agribisnis Tebu Rakyat

\section{KESIMPULAN}

Berdasarkan hasil penelitian dan pembahasan di atas maka dapat ditarik kesimpulan bahwa model peningkatan pendapatan usaha tani tebu di Wilayah Kerja Pabrik Gula Sindanglaut Rayon Pabrik Gula Karangsuwung dipengaruhi langsung oleh perbaikan pola penetapan harga pokok produksi/ harga patokan petani (HPP) dan perbaikan sistem tata niaga gula nasional serta dipengaruhi secara tidak langsung oleh variabel perbaikan pola pembiayaan (kredit) budidaya tebu dan variabel perbaikan produktivitas tebu.

\section{SARAN}

Berdasarkan kesimpulan di atas, maka dapat memberikan saran sebagai berikut:

1. Kepada Pemerintah Republik Indonesia, Pemerintah selaku pihak 
yang memiliki kewenangan dalam membuat kebijakan pengelolaan industri gula nasional, agar dapat memperbaiki pola penetapan harga pokok produksi/ harga patokan petani (HPP) yang layak yaitu sesuai harapan petani sebesar Rp 10.500,- dari sebelumnya Rp 9.700,- dan menghentikan import gula pada saat panen raya tebu yaitu 3 (tiga) bulan sebelum musim giling tebu dan 3 (tiga) bulan setelah musim giling tebu agar gula petani dapat diserap oleh pasar dengan maksimal dan Harga Pokok Produksi/Harga Patokan Petani (HPP) gula di tingkat petani tetap stabil.

2. Kepada pengelola pabrik gula agar dapat melakukan revitalisasi mesinmesin produksi gula milik Badan Usaha Milik Negara (BUMN) sehingga dapat meningkatkan efisiensi proses produksi gula sehingga dapat memberikan proporsi bagi hasil antara petani tebu dan pabrik gula yang lebih besar $(\geq 70 \%=$ meningkatkan HPP $)$.

3. Kepada petani tebu untuk tetap memanfaatkan pembiayaan (kredit) yang diprogramkan oleh pemerintah melalui Kredit Usaha Rakyat (KUR) agar dapat meningkatkan produktivitas dan kualitas tebu giling sehingga dapat meningkatkan pendapatan petani.

4. Kepada para peneliti selanjutnya agar dapat melakukan penelitian lebih mendalam mengenai faktor - faktor lain yang dapat meningkatkan pendapatan usaha tani tebu, agar dapat memperluas pengetahuan dan berkontribusi dalam sektor agribisnis khususnya pada agroindustri gula nasional.

\section{DAFTAR PUSTAKA}

Adhiem, M. A. (2018). Kebijakan Impor Gula: Potensi Dampak dan Upaya Pengamanan Stok Nasional. Jurnal Info Singkat: Kajian Singkat Terhadap Isu Aktual dan Strategis Bidang Ekonomi dan Kebijakan
Publik, $1-6$. http://berkas.dpr.go.id/puslit/files/inf o_singkat/Info Singkat-X-17-IP3DI-September-2018-1904.pdf

Alam, A. S., \& Hermawan, H. (2017). Faktor-Faktor Yang Mempengaruhi Hubungan Kemitraan Antara Petani Budidaya Jamur Tiram. In Agroscience (Vol. 7, Nomor 1). https://jurnal.unsur.ac.id/agroscience /article/view/54/42

Chandio, A. A., Jiang, Y., Rehman, A., \& Akram, W. (2021). Does Formal Credit Enhance Sugarcane Productivity? A Farm-Level Study of Sindh, Pakistan. SAGE Open, 11(1). https://doi.org/10.1177/2158244020 988533

Direktorat Jendral Industri dan Agro Kimia. (2009). Roadmap Industri Gula.

https://www.academia.edu/3094846 2/ROADMAP INDUSTRI GULA

Ghozali, I. (2018). Aplikasi Analisis Multivariate dengan Program IBM SPSS 25. Badan Penerbit Universita Diponogoro.

https://openlibrary.telkomuniversity. ac.id/pustaka/148190/aplikasianalisis-multivariate-denganprogram-ibm-spss-25.html

Ismail, E. (2019). BPS: Pertanian Dongkrak Pertumbuhan PDB Kuartal I 2019. https://www.republika.co.id/. https://www.republika.co.id/berita/e konomi/pertanian/pr311g453/bpspertanian-dongkrak-pertumbuhandb-kuartal-i-2019

Lestari, S. R. (2017). https://finance.detik.com/beritaekonomi-bisnis/d-3546302/tumbuhpositif-sektor-pertanian-sumbangpdb-terbesar-kedua. https://finance.detik.com/. https://finance.detik.com/beritaekonomi-bisnis/d-3546302/tumbuh- 
positif-sektor-pertanian-sumbangpdb-terbesar-kedua

Muaddab, H. (2014). Swasembada gula indonesia: manisnya mimpi dan pahitnya kenyataan. Swasembada gula indonesia: manisnya mimpi dan pahitnya kenyataan, 1-8. https://www.academia.edu/4994250/ SWASEMBADA GULA PAHITN YA MIMPI DAN MANISNYA K ENYATAAN

Negeri, P. K. P. D. (2015). LAPORAN AKHIR ANALISIS LELANG GULA PTPN/PETANI DALAM RANGKA STABILISASI HARGA. http://bppp.kemendag.go.id/media_c ontent/2017/08/ANALISIS_LELAN G_GULA_PTPN_PETANI_DALA M_RANGKA_STABILISASI_HA RGA.pdf

Retherford, R. D. (1993). Statistical models for causal analysis. John Wiley and Sons. http://lib.ui.ac.id/detail?id=2013100 7\&lokasi=lokal

Sanusi, A. (2011). Metodologi Penelitian Bisnis. Salemba Empat. https://search.yahoo.com/search; ylt =Awr9DWf5hN1g7qoA.vFXNyoA; ylc=X1MDMjc2NjY3OQRfcgMy BGZyA21jYWZ1ZQRmcjIDc2ItdG 9wBGdwcmlkAwRuX3JzbHQDM ARuX3N1Z2cDMARvemlnaW4Dc 2VhcmNoLnlhaG9vLmNvbQRwb3 MDMARwcXN0cgMEcHFzdHJsA zAEcXN0cmwDNDYEcXVlcnkDY nVrdSUyME1ldG9kb2xvZ2k1

Saputri, N. K., \& Respatiadi, H. (2018). Reformasi Kebijakan untuk Menurunkan Harga Gula di Indonesia. https://repository.cipsindonesia.org/media/270473- reformasi-kebijakan-untukmenurunkan-har-8c9b5664.pdf

Steiner, D. L. (2005). Finding our way: An introduction to path analysis. Canadian Journal of Psychiatry, 50(2), 115-122. https://doi.org/10.1177/0706743705 05000207

Sudaryono. (2011). Aplikasi Analisis (Path Analysis) Berdasarkan Urutan Penempatan Variabel Dalam Penelitian. Jurnal Pendidikan dan Kebudayaan, $\quad 17(4), \quad 391$. https://doi.org/10.24832/jpnk.v17i4. 36

Sugiyono. (2007). Metode penelitian pendidikan: (pendekatan kuantitatif, kualitatif dan R\&D). Alfabeta. http://lib.ui.ac.id/detail?id=2049625 2\&lokasi=lokal

Sulaiman, A. A., Sulaeman, Y., Mustikasari, N., Nursyamsi, D., \& Syakir, A. M. (2019). Increasing sugar production in Indonesia through land suitability analysis and sugar mill restructuring. Land, 8(4), $1-17$.

https://doi.org/10.3390/land8040061

Suroto. (1992). Strategi pembangunan dan perencanaan kesempatan kerja (Ed.2). Gadjah Mada University Press.

http://opac.lib.ugm.ac.id/index.php? mod=book_detail\&sub=BookDetail \&act=view\&typ=htmlext\&obyek_id $=1 \&$ buku_id=203109

Tayibnapis, A. $\bar{Z}$., Wuryaningsih, L. E., \& Sundari, M. S. (2016). Efforts to Achieve Beyond Sugar in Indonesia. International Journal of Management \& Bisuness Studies, 6(4), 14-22. www.ijmbs.com/Vol6/4/2-ahmadzafrullah-tayibnapis.pdf 